Ciência e Natura, Santa Maria, v. 37 n. 3 set-dez. 2015, p. 849-861

Revista do Centro de Ciências Naturais e Exatas - UFSM

ISSN impressa: 0100-8307 ISSN on-line: 2179-4601

\title{
ciênciaenatura
}

\section{Ensino Médio Inovador e o Estudo dos Problemas Ambientais}

\author{
Innovative School and Study of Environmental al Problems
}

Rachel Faverzani Magnago, Anelise Leal Vieira Cubas, Ana Regina Aguiar, Ivete de Fátima Rossato, Elisa Helena Siegel Moecke

Universidade do Sul de Santa Catarina

\begin{abstract}
Resumo
O artigo socializa práticas pedagógicas desenvolvidas em duas escolas públicas no Estado de Santa Catarina, objetivando dinamizar o processo de ensino-aprendizagem na área de ciências exatas e incentivar os estudantes a ingressarem futuramente em cursos de engenharia. A pesquisa teve um caráter exploratório e descritivo e empregou o ciclo do PDCA para a organização dos resultados. Os projetos realizados nas escolas foram compostos de atividades abordando o tema do meio ambiente. Os resultados apontaram que $95 \%$ dos estudantes gostaram de participar dos projetos, $76 \%$ perceberam com mais facilidade a relação entre teoria e prática e $52 \%$ dos estudantes sentiram-se estimulados a fazer um curso superior na área de engenharias após a participação nesses projetos.
\end{abstract}

Palavras-chave: práticas pedagógicas; escolas públicas; ciências exatas; meio ambiente.

\begin{abstract}
This article aims to socialize teaching practices developed in two public schools in the state of Santa Catarina, aiming to foster the process of teaching and learning in the field of exact sciences and encourage students to enter engineering courses in the future. The research had an exploratory and descriptive nature and used the PDCA cycle to organize the results. The projects carried out in schools were composed of activities addressing the environmental theme. The results showed that $95 \%$ of students enjoyed participating in the projects, $76 \%$ noticed more easily the relationship between theory and practice and $52 \%$ of students felt encouraged to do a degree course in the field of engineering after participating in these projects.
\end{abstract}

Keywords: pedagogical practices; public schools; exact sciences; environment. 


\section{Introdução}

A Lei de Diretrizes e Bases da Educação Nacional (Lei no 9.394/96) prevê, em seu artigo 22, como finalidades do ensino médio, desenvolver o educando, assegurar-lhe a formação comum indispensável para o exercício da cidadania e fornecer-lhes meios para progredir no trabalho e em estudos posteriores (MEC/INEP, 2004).

Os Parâmetros Curriculares Nacionais apontam que o ensino médio deve propiciar aos jovens a aquisição de conhecimentos ligados à preparação científica e à capacidade de utilização de diferentes tecnologias. A consolidação desses conteúdos é de grande importância para o desenvolvimento intelectual dos indivíduos e para o desenvolvimento social e econômico da nação. Eles permitem $\mathrm{o}$ acesso a saberes científicos diversos, de modo que o aluno desenvolva a capacidade de pesquisar, buscar informações, analisá-las e selecioná-las, bem como a capacidade de aprender, criar, formular, ao invés do simples exercício da memorização (Brasil, 2002, p.16).

Sendo assim, quem conclui o ensino médio deve dominar um conjunto amplo de saberes e habilidades, para ser capaz de ingressar ativamente na "sociedade do conhecimento", assumir responsabilidades sociais como cidadão consciente e ético, contribuindo para o desenvolvimento e transformação da sociedade.

Portanto, a educação brasileira para o ensino médio em escolas públicas ainda está longe do exposto acima, com realidades nada otimistas. Segundo Maia (2013), a cada dez alunos, apenas um concluiu o terceiro ano do ensino médio com conhecimento considerado adequado em matemática em 2011. No aprendizado de português, o indicador se manteve estável em $29 \%$ - ou seja, sete de cada dez alunos tiveram desempenho insuficiente. Os dados são parte do relatório anual "De Olho nas Metas" feito pelo movimento Todos Pela Educação. A análise de dados oficiais mostra que o ensino médio continua sendo o grande gargalo da educação brasileira.
Segundo Cieglinski (2013), após a divulgação dos resultados insuficientes das escolas de ensino médio na última edição do Índice de Desenvolvimento da Educação Básica - Ideb 2011, o Ministério da Educação - MEC planeja uma modernização do currículo, propondo a integração das diversas disciplinas em grandes áreas. A inspiração deverá vir do próprio Exame Nacional do Ensino Médio - Enem, que organiza as matrizes curriculares em quatro grandes grupos: linguagens, matemática, ciências humanas e da natureza. Essa é a divisão que segue a prova, diferentemente do modelo tradicional por disciplinas como química, português, matemática e biologia.

Além dos resultados do Ideb, a OCDE (2013), Organização para Cooperação e Desenvolvimento Econômica, anuncia os resultados recentes do Programa internacional de avaliação de estudantes (Pisa), que apresenta o Brasil em $58^{\circ}$ lugar dos 65 países participantes da avaliação.

A pesquisa da OCDE aponta que 49,2\% dos estudantes brasileiros conseguem, no máximo, entender a ideia geral de um texto que aborde um tema familiar ou fazer uma relação simples entre o que foi lido e o conhecimento do cotidiano, onde cerca $0,5 \%$ dos jovens são capazes de compreender um texto desconhecido tanto na forma quanto no conteúdo e fazer uma análise elaborada a respeito. Já em ciências, o desempenho brasileiro também ficou abaixo da média, no mesmo nível de países como a Argentina, Colômbia, Jordânia e Tunísia. O Brasil ficou, nesse item, atrás do Chile, da Costa Rica, do Uruguai e do México, mas à frente do Peru. No entanto, desde 2003, o Brasil conseguiu os maiores ganhos na performance em matemática.

O instrumento empregado pelo Pisa relaciona nas questões da avaliação diferentes conteúdos pertencentes a diferentes disciplinas, apontando para a necessidade da desfragmentação dos conteúdos inseridos nas matrizes curriculares atuais. As causas para os gargalos encontrados são diversos, incluindo a estrutura curricular fragmentada, promovendo estratégias pedagógicas nada atrativas para a realidade 
atual dos estudantes e resultando entre tantas coisas a falta de interesse pelos estudos e pela continuação dos mesmos.

O presente artigo pretende socializar práticas pedagógicas desenvolvidas em duas escolas públicas estaduais no Estado de Santa Catarina, com foco nos estudantes do ensino médio, a partir de projetos aprovados no CNPq. As duas escolas que são objetos de estudo fazem parte do Programa Ensino Médio Inovador. As práticas desenvolvidas objetivaram dinamizar o ensinoaprendizagem do ensino médio, empregando para isso os problemas ambientais e, ainda, aproximar o ensino médio dos cursos de engenharias. $\mathrm{O}$ esforço de aproximar o ensino médio dos cursos de engenharias é significativo e importante, a partir da realidade colocada pelas estatísticas, onde um estudante de cada dez sai com conhecimentos adequados de matemática do $3^{\circ}$ ano do ensino médio.

O Programa Ensino Médio Inovador (ProEMI), instituído pela Portaria no. 971, de 09/10/2009, foi criado para provocar o debate sobre o Ensino Médio junto aos Sistemas de Ensino Estaduais e Distrital fomentando propostas curriculares inovadoras nas escolas do ensino médio, disponibilizando apoio técnico e financeiro, consoante à disseminação da cultura de um currículo dinâmico, flexível e que atenda às demandas da sociedade contemporânea (Brasil, 2013, p.10).

Brasil tem quase 1.500 cursos de engenharia, que oferecem aproximadamente 150 mil vagas por ano. Apesar de tal oferta generosa, o país tem apenas 300 mil estudantes nessa área deveriam ter $750 \mathrm{mil}$, se todas as vagas estivessem preenchidas - e apenas $30 \mathrm{mil}$ se formam anualmente.

Para a indústria, a escassez de engenheiros é um fato preocupante desde 2008. "Mesmo com a recessão em 2009, setores como a construção tiveram demanda além do esperado. Neste período não houve desemprego de engenheiros como os salários, em média, aumentaram $20 \% "$, afirma Marcos Maciel Formiga, representante da Confederação Nacional da Indústria (CNI) e membro da comissão da Capes. Para ele, se a taxa de crescimento econômico continuar acima de $5 \%$, haverá necessidade de duplicar o número de engenheiros formados anualmente.

Sem engenheiros qualificados, não há como implementar nenhum projeto de desenvolvimento nacional. $\mathrm{O}$ Brasil precisa dobrar o atual número de engenheiros para garantir um crescimento econômico da ordem de $5 \%$ ao ano. E precisa triplicar esse número se quiser ter o mínimo de competitividade no cenário internacional. A oferta de engenheiros no mercado de trabalho não será suficiente para atender à demanda da indústria, da agroindústria, do comércio e das áreas de tecnologia até 2020.

Vários são os estudiosos que buscam desenvolver formas de tornar as aulas de matemática, química e física mais significativas aos estudantes do ensino médio. Massena et al (2013) corroboram com esse objetivo ao salientar que a formação inicial de professores ao longo dos anos tem incorporado em sua prática distintas formas de trabalho com o intuito de promover melhorias no Ensino de Ciências realizado na Educação Básica pelos futuros docentes. Dentre elas pode-se citar a realização de oficinas, com propostas de atividades experimentais sobre temas diversos; a produção de jogos didáticos; softwares educativos; o uso de portfólios; diários e dentre outros.

A prática pedagógica, segundo Almeida (1999), por meio de desenvolvimento de projetos procura envolver tanto $\mathrm{o}$ aluno quanto $\mathrm{o}$ professor, os recursos disponíveis e todas as intenções que se estabelecem nesse ambiente. Essa perspectiva implica que o papel da escola não é somente ensinar conteúdos, nem vincular a instrução com aprendizagem, mas preparar os alunos para um convívio responsável e atuante na sociedade.

Amaral e Guerra (2012) trabalharam os conteúdos de Ciência com estudantes do ensino fundamental por meio de projetos, onde os estudantes se envolveram em uma experiência em que o processo de construção do conhecimento esteve ligado às práticas vividas levando-os ao interesse pela Ciência. Esse trabalho procurou utilizar a pedagogia de projetos para ensinar conceitos químicos a partir do tema "água". Por meio de atividades teóricas e práticas e visitas de campo, foi possível organizar melhor a aprendizagem dos alunos a partir das questões e discussões que foram surgindo com o desenvolvimento do projeto. Pode-se dizer que, por meio dessa iniciativa, os alunos demonstraram um interesse maior pela 
Química e puderam construir relações conceituais mais efetivas.

Cita-se ainda e de forma importante as contribuições de Demo (1997) para tornar o processo de ensino-aprendizagem um caminho atrativo e significativo aos nossos estudantes, a partir da pesquisa. Demo (1997) aponta para a pesquisa como uma maneira própria de aprender. Nessa nova maneira de aprender, o estudante passa de objeto do ensino para parceiro de trabalho, assumindo-se sujeito do processo de aprender. Segundo Demo a pesquisa deve ser considerada como elemento chave no processo de aprendizagem das escolas e das universidades, pois a pesquisa busca instigar o aprendiz, incentivando-o a participar do processo de reconstrução do conhecimento que efetivamente leva a aprendizagem (Bertoletti et al, 2003).

\section{Materiais e Métodos}

O presente estudo é uma proposta de cunho qualitativo, realizada em duas escolas estaduais do ensino médio: Escola de Educação Básica Laércio Caldeira de Andrada e Escola de Educação Básica Cecília Rosa Lopes, participantes do Programa Ensino Médio Inovador do Governo Federal e localizadas no município de São José - Estado de Santa Catarina.

O artigo é resultado de dois projetos aprovados no $\mathrm{CNPq}$ e que contou com a participação de 150 estudantes do ensino médio das duas escolas e 6 estudantes dos cursos de Engenharias da Universidade do Sul de Santa Catarina (Unisul) e, ainda, 2 professores das duas escolas e 6 professoras da Unisul. A coleta de dados começou em fevereiro de 2013 durante os encontros de planejamentos até a fase de verificação, dezembro de 2013. Os projetos realizados nas escolas foram compostos de oficinas: construção de protótipos, visitas técnicas e aulas experimentais em laboratórios da Unisul.

O referido estudo possui também cunho cientifico acadêmico e tem por método a pesquisa exploratória e descritiva. Segundo Andrade (2006), as pesquisas exploratórias buscam informações obtidas através de fontes bibliográficas com a finalidade de aprofundar determinados assuntos, definindo objetivos ou formulando hipóteses de uma pesquisa. Já a pesquisa descritiva tange aos fatos descritos, observados, registrados, analisados sem interferência do pesquisador. $O$ trabalho realizado baseia-se na observação dos fatos tal como ocorreu na realidade das duas escolas de ensino médio da cidade de São José-SC.

A primeira visita dos professores da Unisul, responsáveis pelos projetos, nas escolas teve como finalidade o conhecimento do local e das pessoas envolvidas, a saber: professores, funcionários, supervisores pedagógicos e diretores. A segunda visita teve como objetivo apresentar os projetos aos estudantes do ensino médio das duas escolas. Nas visitas posteriores aconteceram os planejamentos das atividades, buscando inseri-las no cronograma das escolas. Quinzenalmente, aconteciam reuniões das equipes (professores e estudantes bolsistas da Unisul e professores e estudantes bolsistas das escolas) com intuito de detalhar cada atividade a ser realizada, em termos, por exemplo, dos conteúdos específicos das disciplinas a serem explorados e o formato das oficinas.

Para o referido artigo, empregar-se-á o ciclo gerencial PDCA, conforme ilustra a figura 1, como forma de sistematizar as informações e os resultados obtidos com os projetos desenvolvidos nas escolas.

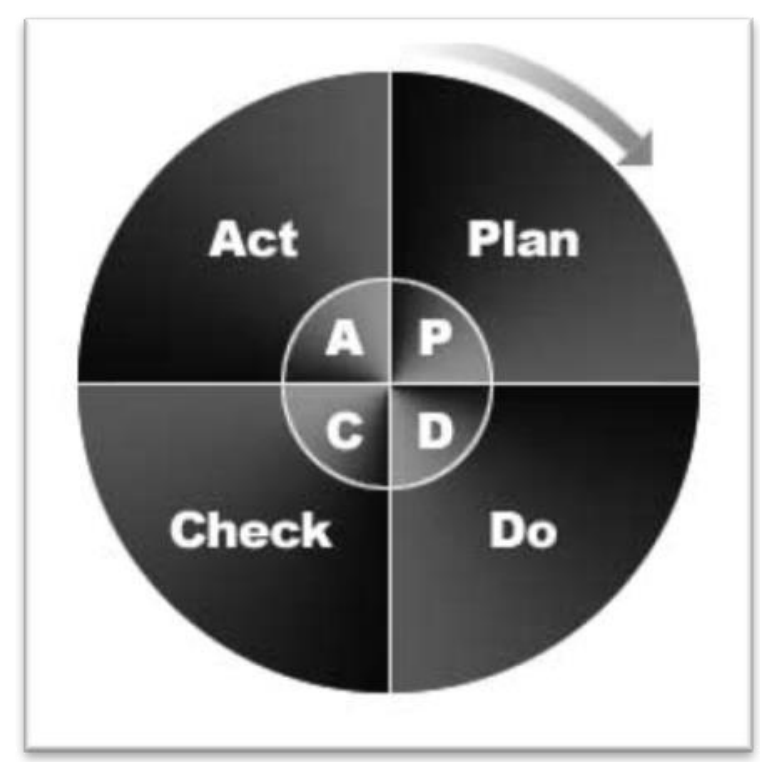


Figura 1- ciclo PDCA (Campos, 2004)

Segundo Monteiro et al (2013), a sigla vem do inglês e representa as quatro etapas de realização do ciclo: Plan, Do, Check e Act. A etapa $\mathrm{P}$ (Planejamento) é aquela na qual o problema é definido e sua relevância é reconhecida, realizando observações sobre diferentes pontos de vista e a análise para descoberta das causas originais do problema. $\mathrm{Na}$ etapa D (Execução), é onde o plano anteriormente elaborado é posto em prática como forma de interferir nessas causas fundamentais. A etapa C (Verificação) é realizada para verificar se as ações tomadas se mostraram positivamente efetivas e satisfatórias aos objetivos planejados. E a etapa A (Ação) que é a última realizada dentro do ciclo, correspondente ao estabelecimento de um novo procedimento operacional ou reavaliação de um antigo procedimento, educando e treinando pessoal para a execução do procedimento operacional padrão, sendo frequentemente acompanhado o cumprimento dos padrões (Werkema, 1995).

A partir do exposto apresentam-se as quatro etapas do ciclo PDCA adaptadas aos interesses do presente estudo.

Etapa I: PLAN - Planejamento: Nessa primeira etapa foram feitos os planejamentos (planos de ação) das atividades desenvolvidas nas escolas, um para cada escola. Os planejamentos foram construídos de forma participativa, envolvendo as equipes da Unisul e das escolas, bem como dos estudantes bolsistas e, ainda, dos diretores, para estabelecer os objetivos dos projetos, os conteúdos das disciplinas, os formatos das oficinas, e por fim os cronogramas de execução.

Etapa II: DO - Execução: Essa etapa consistiu na execução do planejamento e na capacitação dos envolvidos e, ainda, foram abordados os seguintes passos:

- Apresentação das oficinas aos estudantes das escolas, abordando os temas a serem trabalhados ao longo da duração dos projetos (12 meses);

- $\quad$ Capacitação dos estudantes bolsistas (da Unisul e das escolas) e professores (das escolas) para as execuções das atividades do projeto;

Preparação dos conteúdos relacionados com as práticas. Ou seja, preparar as atividades para que eles pudessem relacionar a teoria (conteúdos das disciplinas de Matemática, Física e Química) com a prática, por meio de oficinas. As oficinas se constituíram de construções de protótipos, palestras, pesquisas bibliográficas e de campo, visitas técnicas, experimentos nos laboratórios da Unisul.

Construção e execução das oficinas (protótipos, realização de pesquisas bibliográficas e de campo, visitas técnicas).

Etapa III: CHECK - Verificar: A terceira etapa foi a verificação dos resultados alcançados. Ela pode ocorrer concomitantemente com a realização do planejamento quando se verifica a efetividade do trabalho ou após a execução quando são feitas as análises das informações e a verificação dos itens de controle. Nessa etapa, ainda, os estudantes das escolas puderam expor suas percepções quanto aos resultados obtidos. Todas as oficinas realizadas foram registradas por meio de fotografias, redes sociais, relatórios, trabalhos em salas de aulas, cartazes e protótipos.

Etapa IV: ACT - AGIR: Nessa etapa foi feita a análise crítica dos planejamentos (planos de ação), buscando formatar melhorias continuas a serem feitas após as conclusões dos projetos e para ações futuras.

\section{Práticas Pedagógicas}

Na etapa do ciclo PDCA, no "fazer" iniciaram-se as oficinas propriamente ditas com os estudantes do ensino médio, sendo elas: Sistemas simples de reaproveitamento da água da chuva; Sistema de Aquecimento de água a partir da energia solar; Sistema de conversão de energia mecânica em energia elétrica; Visita técnica a uma micro-usina de biodiesel; Composteira para produção de húmus.

Oficina 1: Sistemas simples de reaproveitamento da água da chuva

Essa oficina objetivou trabalhar os princípios da química e da física de forma teórico-práticos, por meio da construção de um protótipo pelos estudantes que recircula a água 
da chuva com propósito de gerar vácuo para os laboratórios de química.

Os princípios da química trabalhados dizem respeito aos três estados clássicos da matéria, ligações químicas intermoleculares e intramoleculares, solubilidades de compostos, tipos de misturas, métodos de separação das misturas, funções inorgânicas e potencial hidrogeniônico (Sanson, 2013, Marson, 2013)

Os princípios da física foram trabalhados quando da geração do vácuo, principalmente, conteúdos relacionados à pressão de vapor d'agua com influencia da temperatura, vasos comunicantes, força e movimento (Imbroisi et al, 2009).

Com o desenvolvimento do protótipo os estudantes pesquisaram o uso da trompa de vácuo nas atividades de um laboratório de química, sendo que os principais usos são: filtração, destilação, sublimação e secagem de produtos por vácuo.

A figura 2 apresenta: a) projeto do sistema de aproveitamento da água da chuva; (b) sistema previamente finalizado.
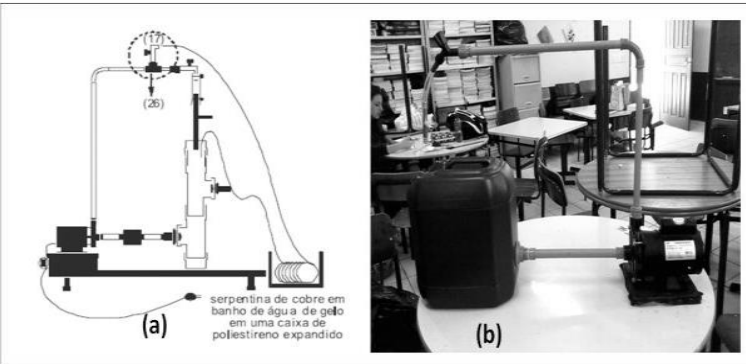

Figura 2: (a) Projeto do sistema de aproveitamento da água da chuva; (b) sistema previamente finalizado. (a) MORRISON (2005); (b) Autores

Oficina 2: Sistema de Aquecimento de água a partir da energia solar

Nesta oficina foram aplicados princípios da física relacionados com as formas de transmissão de calor como a convecção, que é um dos principais modos de transferência de calor e transferência de massa e conversão de escalas termométricas. Além dos princípios da física, alguns princípios da matemática (trigonometria) e da geografia (coordenadas magnéticas e geográficas) foram também trabalhados nessa oficina.

Os estudantes inicialmente fizeram uma pesquisa nos acervos da biblioteca da Unisul e da escola e na internet sobre a energia solar e, ainda, sobre os materiais a serem usados para a construção de um sistema de aquecimento de água.

Após este estudo teórico, os estudantes fizeram uma visita técnica para conhecer um sistema de aquecimento de água funcionando, a partir da energia solar, instalado na micro-usina de Biodiesel na comunidade da Praia da Pinheira (Palhoça/Santa Catarina), onde a água quente é usada no processo de purificação para a produção de biodiesel.

Os estudantes fizeram também a separação do material reciclável (garrafas pet de 2 litros e caixas de leite tetra pack), em suas casas, para ser usado na construção dos painel solar. Nas escolas as garrafas e as caixas foram devidamente limpas e preparadas para a montagem do painel. A figura 3 mostra o painel solar construído pelos estudantes em fase de testes.

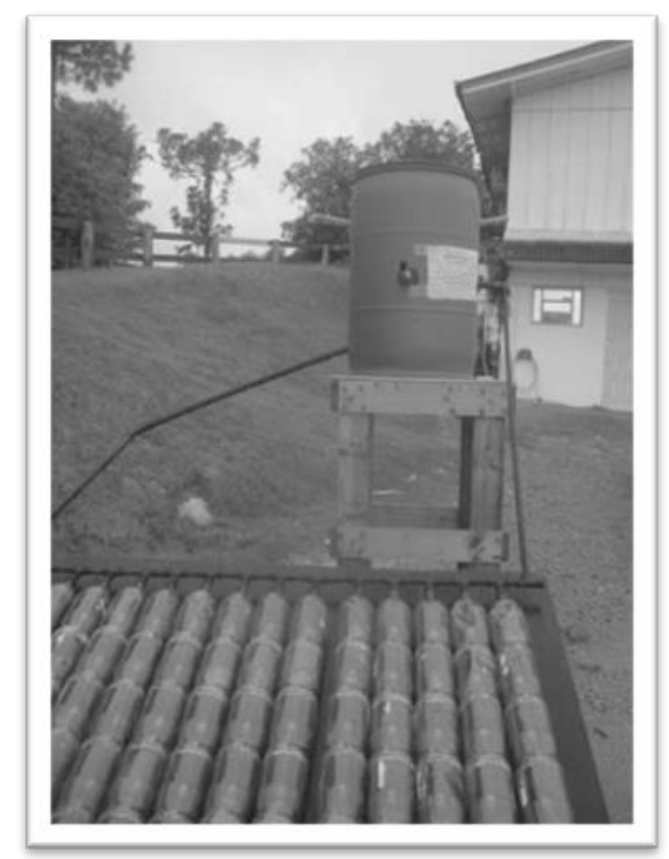

Figura 3: Painel solar construído pelos estudantes. 
$\mathrm{Na}$ referida oficina, os estudantes puderam compreender o processo do aquecimento da água por meio da transmissão de calor por convecção. A água se aquece, por estar em contato com uma superfície quente (painel), e nesse momento tem suas moléculas agitadas, aumentando seu volume e tornando-a menos densa. Isso acarreta o fenômeno físico conhecido como "estratificação" e faz com que, em um mesmo meio, a água fria desça e a água quente suba.

Além dos conteúdos de física envolvidos, salientaram os conteúdos de matemática e de geografia para a instalação do sistema de aquecimento de água (figura 3). A instalação do painel foi voltada para o norte geográfico, visando maior absorção dos raios solares ao longo do dia, e com um ângulo de inclinação igual ao da latitude local acrescido de aproximadamente $10^{\circ} \mathrm{C}$, pois abaixo disso fica comprometida a circulação por termossifão. $\mathrm{O}$ município de São Jose, onde as escolas estão situadas, se encontra na latitude $27^{\circ}$ mais $10^{\circ}$, teremos $37^{\circ}$ de inclinação do painel em relação a superfície. Colocar o painel na angulação correta permite que os raios solares sejam aproveitados ao máximo, fazendo assim com que o sistema permaneça quente por mais tempo. Os sistemas de aquecimento instalados nas escolas apresentaram uma eficiência de aproximadamente $34 \%$ durante os meses de agosto a outubro.

Oficina 3: Sistema de conversão da energia mecânica em energia elétrica

A oficina teve como objetivo a construção de um protótipo para converter energia mecânica em energia elétrica, envolvendo os estudantes e professores das escolas e da Unisul.

As usinas hidrelétricas utilizam geradores que tem o mesmo princípio dos dínamos de bicicleta, ambas são construídos de forma semelhante e produzem energia elétrica a partir da energia mecânica de rotação de um eixo.

Quando o dínamo está em contato com a roda, o seu movimento de rotação é transferido para o eixo do dínamo pelo contato com o pneu. Quando se coloca um imã fixado ao eixo, ele fica girando entre as bobinas. Esse movimento que é responsável pelo acendimento do farol da bicicleta.

Os princípios do eletromagnetismo foram trabalhados no funcionamento do dínamo que ilustra um caso particular de uma das quatro leis gerais do Eletromagnetismo: a lei de Faraday, segundo a qual uma corrente elétrica é gerada num circuito fechado sempre que houver variação de um campo magnético nessa região.

O princípio da conservação da energia pode ser explicado no acendimento do led ligado ao dínamo, não há como o ímã parado "bombear" energia, continuamente, para a lâmpada, para que isso ocorra é preciso fornecer energia, e isso é feito pelo movimento, ou seja, a bicicleta tem que estar em movimento para acender o farol ou girar o eixo do dínamo para acender o led.

Os estudantes foram divididos em equipes, cada equipe construiu uma maquete, simulando áreas urbana, rural, industrial e litorânea, os materiais empregados eram resíduos (caixas de fósforo e de remédio), fixados em folhas de isopor com dimensões 100x100 cm, as caixas simularam residências, chácaras, indústrias e os palitinhos de churrasco como postes, que por sua vez foram conectados a pequenas lâmpadas de led. Essas lâmpadas foram ligadas a um dínamo, por meio de fios, o qual foi fixado no eixo da roda de uma bicicleta. Na sequencia, a bicicleta é fixada em um suporte que permitiu movimentar as rodas sem deslocala do lugar, para então acionar os leds e iluminar as maquetes.

Oficina 4: Visita técnica a uma micro-usina de biodiesel

Os estudantes foram ver de perto a produção de biodiesel a partir de óleo de fritura em uma micro-usina instalada na comunidade da Praia da Pinheira (Palhoça/Santa Catarina). Nesse momento foram explicadas com detalhes as reações químicas presentes na produção do biodiesel e, ainda, foi mostrado como se separa a glicerina do biodiesel para a produção do sabão. 


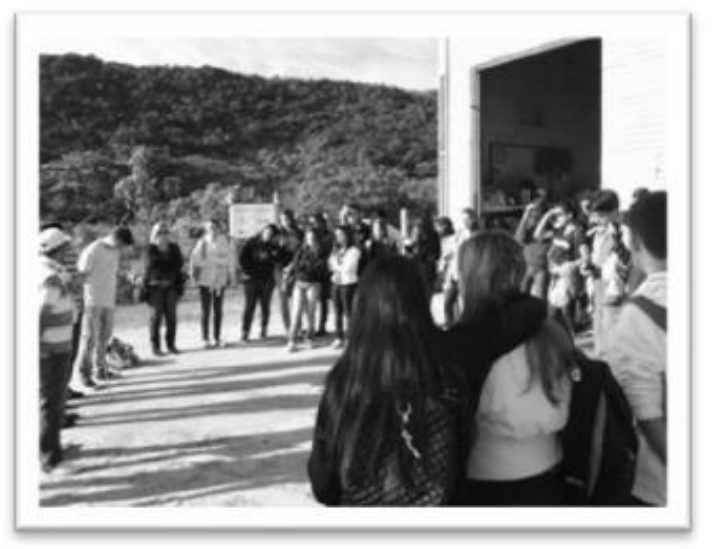

Figura 4 - Recepção dos estudantes pela presidente da Pro-Crep

A presidente da Pro-Crep, associação da referida comunidade que opera a micro-usina, recepcionou e deu uma aula de educação ambiental aos estudantes (figura 4), salientando que o biodiesel produzido vem de um resíduo (óleo de fritura) e dos impactos ambientais provocados quando o óleo de fritura é lançado na natureza.

A micro-usina tem uma área para o tratamento de seus efluentes que acontece por meio de um sistema de zona de raízes. O sistema de zonas de raízes, representado na figura 5, é considerado um método de tratamento que utiliza tecnologia simples, de fácil operação e de custo baixo. Este sistema dispõe de materiais de preenchimento (brita, areia, cascalho). Dentre os numerosos mecanismos que causam essa remoção, destacam-se a decantação (efeito peneira causado pelo biofilme microbiano aderido às raízes e ao substrato), o predatismo e a competição entre outros microrganismos e eventuais substâncias tóxicas produzidas pelas plantas e liberadas através de suas raízes (SILVA BRITO et al., 2007). Grafias et al (2010) usaram este sistema para o tratamento de efluentes provenientes da indústria de extração de óleo de oliva, os resultados obtidos mostram uma redução de $86 \%$ na cor e $77 \%$ de redução na DQO (demanda química de oxigênio).

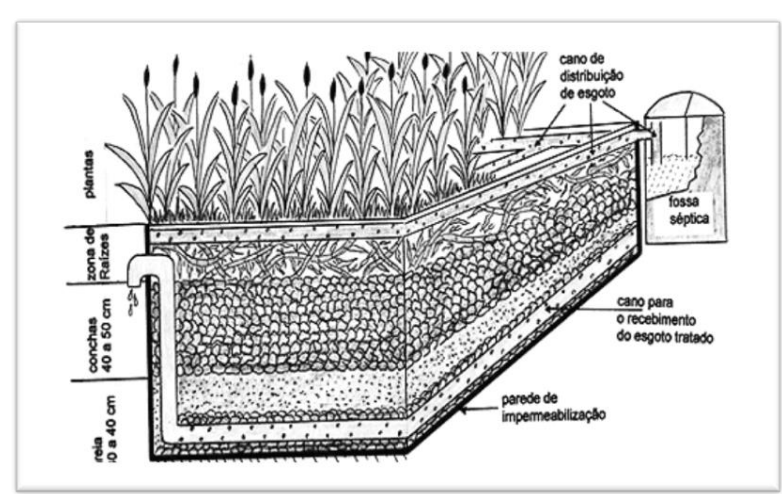

Figura 5 - Sistema de zona de raízes

Fonte: Disponível em:

<http://omicronblog.blogspot.com.br/2011/0 3/tratamento-de-esgoto-por-raizes.html >

Acesso em: 12 abril de 2015.

Durante a visita buscou-se explicar aos estudantes os conteúdos de matemática envolvidos na construção da zona de raízes, como por exemplo, o cálculo da área, o volume de efluentes a ser tratado e o ângulo de inclinação da mesma, ainda, fizeram conversões de medidas. Além dos conteúdos matemáticos, foram trabalhados aqueles relacionados às disciplinas de Biologia e de Química no que tange ao funcionamento da zona de raízes para tratar o efluente da micro-usina.

Oficina 6: Composteira para a produção de húmus

A presente oficina teve como objetivo relacionar vários conteúdos das disciplinas de Biologia, Matemática, Química e Física com a construção de uma composteira, a qual serviu para produzir húmus para a horta e o jardim das escolas, a partir de resíduos orgânicos das refeições dos estudantes.

A compostagem é a "reciclagem dos resíduos orgânicos": é uma técnica que permite a transformação de restos orgânicos (sobras de frutas e legumes e alimentos em geral, podas de jardim, trapos de tecido, serragem, etc) em adubo. É um processo biológico que acelera a decomposição do material orgânico, tendo como produto final o composto orgânico (Ministério do Meio Ambiente, 2013).

Primeiro um dos estudantes bolsistas da Unisul apresentou aos estudantes das escolas o passo a passo de como fazer uma composteira bem como os fundamentos de matemática, física, química e biologia envolvidos nesse processo. E, 
ainda, mostrou os benefícios de uma composteira, a saber: fornece material rico em nutrientes que melhora o desenvolvimento de plantas; atua no solo como uma esponja, ajudando a reter a umidade e nutrientes; ajuda a melhoras as características do solo, são menos afetados pela erosão; usado no lugar de fertilizantes químicos entre outros.

Para construir a composteira empregaram-se os fundamentos de geometria, trigonometria e outros (figura 6). A composteira feita tem dois compartimentos para facilitar o manejo do resíduo.

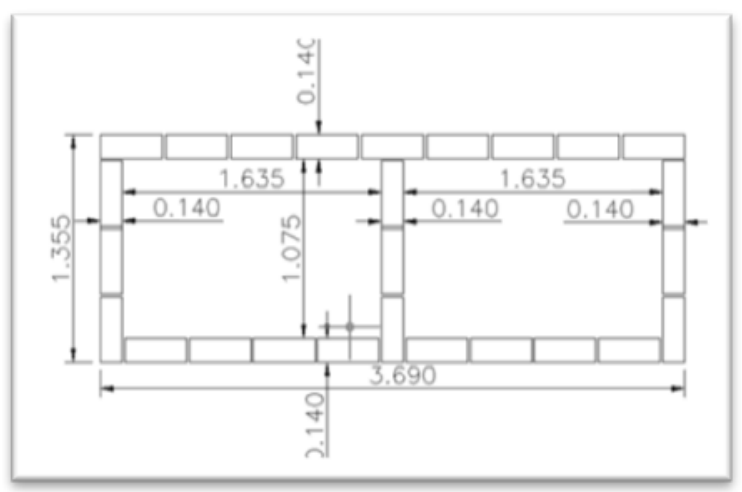

Figura 6 - As medidas e formato da composteira

Na figura 7 apresentam-se os estudantes e professores envolvidos na construção da composteira.

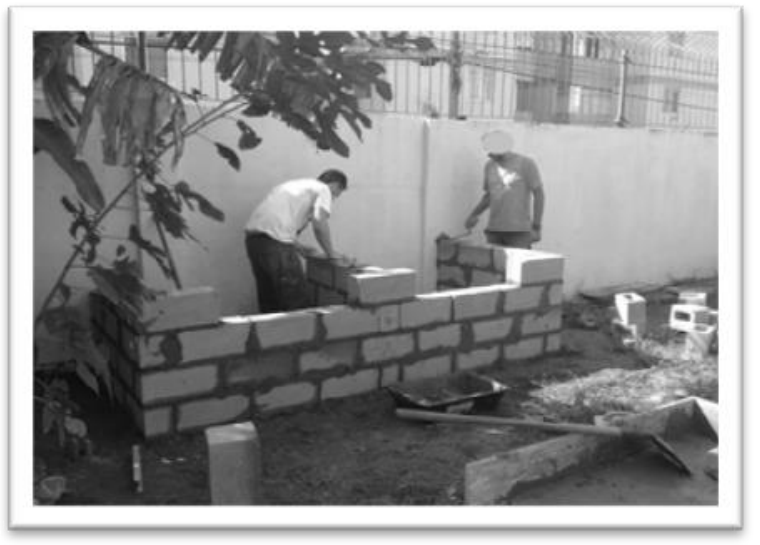

Figura 7 - Estudantes envolvidos na construção da composteira
Os estudantes aprenderam sobre quais resíduos deverão ser utilizados na composteria: resíduos domésticos, aparas de gramas, cinzas; folhas, jornais, serragem. Sugere-se colocar os resíduos domésticos, neste caso, das refeições da escola e cobri-los com serragem, folhas, para evitar a proliferação de moscas. Após algum tempo, este material deverá ser remexido, mudando de local, dentro do espaço da figura 8. Nesta etapa ocorre a fermentação dos resíduos, ou seja, acontece o tratamento biológico. O processo deve ser repetido até produzir o adubo para ser utilizado na horta e nos jardins das escolas.

Figura 8 - Composteira construída nas escolas

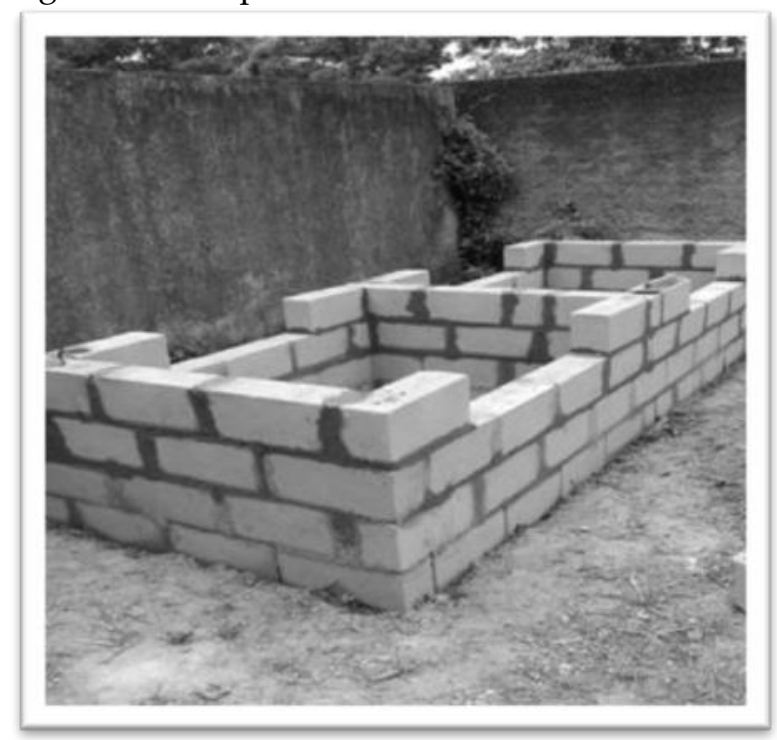

Fonte: Autores

Oficina 6: Produção de placas de circuitos impressos em escala laboratorial

A oficina em questão envolveu os estudantes do $3^{-}$ano das escolas e das engenharias da Unisul, onde os professores responsáveis (das escolas e da Unisul) abordaram conteúdos da disciplina de Física, como resistência, tensão e corrente elétrica, primeira Lei de Ohm e associação de resistores (série, paralelo e misto) e, ainda, das disciplinas de Química (reações químicas) e de Matemática (cálculos de potenciais elétricos).

Normalmente, estes conteúdos são vistos como vilões pelos estudantes, mas, no entanto, quando apresentados de forma prática, aplicada no dia a dia, o aprendizado se torna significativo. 
A oficina começou com a discussão da teoria acerca dos assuntos já apontados e na sequencia aconteceu a prática.

As placas de circuito impresso, também conhecidas como PCIs, geralmente não estão à vista, mas elas fazem parte de tudo o que envolve tecnologia: computadores, cadeiras automatizadas (como as de dentistas), sistemas de segurança, smartphones, brinquedos, carros e chuveiros são apenas alguns exemplos de dispositivos que usufruem dessas placas repletas de componentes eletrônicos para desempenhar suas respectivas funcionalidades. Apesar de estarem ocultas as PCIs são extremamente importantes no nosso dia a dia.

Um circuito impresso consiste em uma placa formada por camadas de materiais plásticos e fibrosos (como fenolite, fibra de vidro, fibra e filme de poliéster, entre outros polímeros) que conta com finas películas de substâncias metálicas (cobre, prata, ouro ou níquel). Essas películas formam as "trilhas" ou "pistas" que serão responsáveis pela condução da corrente elétrica pelos componentes eletrônicos (figura 9). Esses impulsos elétricos são transmitidos para os componentes, viabilizando o funcionamento de cada peça e, consequentemente, do sistema completo formado pela PCI.

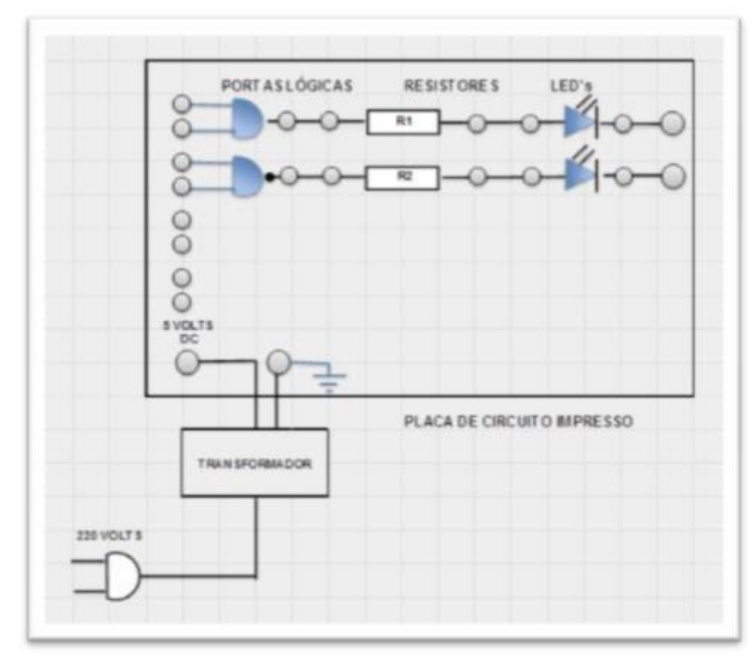

Figura 9 - Placa de circuito Impresso

Na sequencia, a figura 10 apresenta os estudantes em prática.

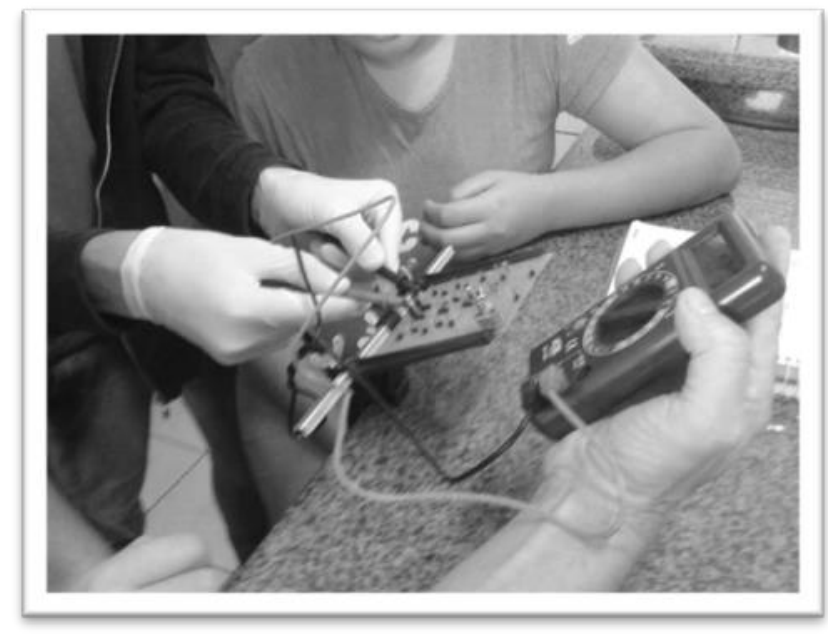

Figura 10 - Estudantes nas atividades práticas

Depois das PCIs prontas, os estudantes puderam usá-las em uma situação real, por exemplo, iluminar uma maquete de uma cidade.

\section{Considerações Finais}

O ciclo PDCA que é composto por quatro etapas (P - planejamento, D - fazer, C checar/verificar e A - agir de forma corretiva) nos permitiu a sistematização das informações e dos resultados dos projetos, detalhando as atividades em termos dos responsáveis, dos cronogramas, dos locais e de execução das mesmas.

Cada oficina teve suas particularidades em relação ao envolvimento dos estudantes, como por exemplo, as oficinas do aproveitamento da água da chuva e do sistema de aquecimento solar exigiram dos estudantes habilidades com o uso de ferramentas para montagem dos canos, bomba e conexões, já na oficina da energia elétrica a partir da energia mecânica foi trabalhada a criatividade na arte de montagem das maquetes e explorado habilidades com instalações elétricas.

Portanto, a riqueza das oficinas se deu na relação teoria-prática, as quais exploram de forma prática muitos conteúdos das matrizes curriculares do ensino médio, a exemplo da 
matemática, física e química, tornando os conteúdos mais interessantes, dinâmicos e principalmente factíveis.

As práticas pedagógicas apresentadas aqui nesse artigo foram baseadas em soluções simples para problemas ambientais, buscando-se junto aos estudantes o equacionamento dos problemas através do desenvolvimento de projetos devidamente fundamentados nos princípios teóricos que possibilitaram a experimentação, a simulação, a demonstração e a sistematização.

Nessa etapa ainda de "checar" foi feito um questionamento com os estudantes das duas escolas por meio de uma dinâmica de grupo, para verificar a efetividade do projeto. $\mathrm{Na}$ dinâmica foi avaliado o envolvimento dos estudantes nas atividades propostas e suas percepções quanto à relação das oficinas com os conteúdos das disciplinas de matemática, química e física. Observou-se que $95 \%$ dos estudantes gostaram de participar do projeto, sendo que $76 \%$ perceberam a relação da teoria das disciplinas com a prática nas oficinas, além facilitar na compreensão dos referidos conteúdos. Também constatou-se que $71 \%$ gostariam de continuar com aulas práticas, conforme proposto no projeto. Também se observou que $52 \%$ dos alunos sentiram-se estimulados a fazer um curso superior, principalmente, na área das engenharias após a participação nesse projeto.

Após avaliar os resultados obtidos, de acordo com o ciclo PDCA, na etapa do "agir" foi realizada uma análise crítica dos projetos, constatando-se a necessidade de estender os projetos para os diferentes níveis das escolas. Estudantes de todos os níveis podem ter o processo de ensino-aprendizagem incrementado de alguma forma através das atividades propostas, podem ser trabalhados conteúdos de disciplinas de educação ambiental com estudantes do ensino fundamental, bem como aqueles ligados a matemática e a ciência.

A participação em feira de ciências e/ou gincanas é outra sugestão de melhoria no processo de ensino e aprendizagem, onde o estudante terá a oportunidade de desenvolver protótipos e maquetes, trazendo desta forma a discussão científica para a escola. De acordo com
Bernardes (2012) "as feiras de ciências constituem-se em recursos riquíssimos para divulgação de ciência na comunidade escolar". É nas feiras de ciências, segundo Moura (2012), que "os alunos têm a oportunidade de desenvolver habilidades importantes decorrentes da conjunção entre as duas dimensões básicas do conhecimento: a teoria (junto à razão) e a experimentação junto ao fenômeno real da natureza".

A feira é uma maneira de abrir a escola para discutir questões ambientais e/ou sociais, como também para estudar problemas de seu entorno (GONÇALVES, 2008). Além disso, é uma oportunidade de democratização do conhecimento científico e de aproximação das comunidades às escolas, exercendo "um efeito catalisador sobre as ações pedagógicas das escolas, ao integrar uma função social real à produção do conhecimento (antes apenas de caráter simbólico) ali desenvolvida" (FALTAY \& OLIVEIRA, 2008, p.219).

Nas discussões dos Parâmetros Curriculares Nacionais para o Ensino Médio, no que tange a parte III que trata das Ciências da Natureza, Matemática e suas Tecnologias, salienta-se um parágrafo que apresenta diferentes fenômenos presentes no dia a dia das pessoas, os quais podem, na grande maioria das vezes, ser explicados pelos conhecimentos físicos, químicos e matemáticos, de forma articulada e não fragmentada, o que torna a aprendizagem significativa.

Ainda no documento citado (Brasil, 2000, p.9), tem-se que:

[...]. Por isso tudo, o aprendizado deve ser planejado desde uma perspectiva a um só tempo multidisciplinar e interdisciplinar, ou seja, os assuntos devem ser propostos e tratados desde uma compreensão global, articulando as competências que serão desenvolvidas em cada disciplina e no conjunto de disciplinas, em cada área e no conjunto das áreas. Mesmo dentro de cada disciplina, uma perspectiva mais abrangente pode transbordar os limites disciplinares.

As oficinas apresentadas ao longo deste artigo buscou dar uma perspectiva multi e interdisciplinar para os conteúdos envolvidos 
nas disciplinas, mas sem perder as particularidades de cada uma delas.

\section{Agradecimentos}

Agradecimentos ao CNPq.

\section{Referências}

Almeida, M. E. B. (1999). Educação: Uma nova cultura da aprendizagem. Educação Publica, Rio de Janeiro: Fundação Cecierj; Jul. 1999. Disponível em: $<$ http://www.educacaopublica.rj.gov.br/biblio teca/educacao/0030.html> Acesso em: $01 \mathrm{dez}$. 2013.

Amaral, C. L. C., Guerra, A dos S. (2012). Utilizando a pedagogia de projetos para despertar o interesse da ciência em alunos do Ensino Fundamental II. Ciência em tela, Rio de Janeiro, 5(1), 1-8.

Andrade, M. M. (2006). Introdução a Metodologia de Trabalho Cientifico. $7^{\mathfrak{o}}$ ed. São Paulo: Atlas.

Bernardes, A. O. (2011). Algumas considerações sobre a importância das feiras de Ciências. Educação Publica, Rio de Janeiro: Fundação Cecierj; Disponível em: $<$ http://www.educacaopublica.rj.gov.br/biblio teca/educacao_em_ciencias/0006.html> Acesso em: 02 jul. 2014.

Barros, A. J. Da S., Lehfeld, N. A. de S. (2007) Fundamentos de Metodologia Científica. 3. ed. São Paulo: Pearson Prentice Hall.

Bertoletti, A. C., Moraes, M. C., Moraes, R., Costa, A. C. da R. (2003) Educar pela Pesquisa: uma abordagem para o desenvolvimento e utilização de Softwares Educacionais. Revista Novas Tecnologias na Educação, Universidade Federal do Rio Grande do Sul: CINTED; Porto Alegre, 1(2), $1-10$.

Brasil. (2000). Secretaria de Educação Média e Tecnológica. Parâmetros Curriculares Nacionais: Ensino médio. Parte III - Ciências da Natureza, Matemática e suas Tecnologias. Brasília: MEC/Semtec. Disponível em $<$ http://portal.mec.gov.br/seb/arquivos/pdf/14 _24.pdf> Acesso em: 12 mar. 2014.
. (2002). Secretaria de Educação Média e

Tecnológica. Parâmetros Curriculares

Nacionais: ensino médio. Brasília:

MEC/Semtec.

(2013). Ministério da Educação. Secretaria de Educação Básica. Diretoria de currículos e educação integral. Programa ensino médio inovador: documento orientador.

Campos, V. F. (2004). Gerenciamento da rotina do trabalho do dia-a-dia. $8^{\underline{a}}$ Ed. Belo Horizonte: Editora de Desenvolvimento Gerencial.

Cieglinski, A. (2012). Novo currículo do ensino médio poderá ser inspirado no Enem. Brasília. Disponível em $<$ http://educacao.uol.com.br/noticias/2012/08/ 17/novo-curriculo-do-ensino-medio-poderaser-inspirado-no-enem.htm> Acesso em: 12 nov. 2013.

Demo, P. (1997). Educar pela Pesquisa. Campinas, SP: Autores Associados.

Faltay, P., Oliveira, A. J. S. (2008). Itinerância e Encontro de Ciências. p. 217-220. In: PAVÃO, A. C. \& FREITAS, D. Quanta Ciência há no Ensino de Ciências. São Carlos: EDUFSCar,.

Gonçalves, T. V. O. (2008). Feiras de Ciências e Formação de professores. p. 207-215. In:PAVÃO, A. C. \& FREITAS, D. Quanta Ciência há no Ensino de Ciências. São Carlos: EDUFSCar.

Goldenberg, M. (2007). A arte de pesquisar: como fazer pesquisa qualitativa em ciências sociais. Rio de Janeiro: Record.

Grafias, P., Xekoukoulotakis, N. P., Mantzavinos D., Diamadopoulos, E. (2010). Pilot treatment of olive pomace leachate by vertical-flow constructed wetland and electrochemical oxidation: An efficient hybrid process. Water Research. 9(44), 2773-2780.

Imbroisi, D. O., Santana, C. S. T., Araújo, C. R. M., Silva, W. C., Lopes, C. B. (2009). Construção de um sistema simples e compacto de recirculação d água sob pressão para trompa d água. Química Nova, São Paulo: SBQ. 32(1), 234-236.

Maia, W. (2013). Ensino Médio Piora: 9 Em 10 alunos deixam escola sem saber matemática. 
São Paulo. Disponível em: $<$ http://educacao.uol.com.br/noticias/2013/03/ 06/ensino-medio-piora-9-em-10-alunosdeixam-escola-sem-saber-matematica.htm> Acesso em: 10 nov. 2013.

Teruya, L. C., Marson, G. A., Rezende, C. M. de, Viana, M. H. (2013). Imagem pública e divulgação da química: desafios e oportunidades. Química Nova, São Paulo: SBQ, 36(10), 1561-1569.

Massena, E. P., Guzzi Filho, N. J., Sá, L. P. (2013). Produção de casos para o ensino de química: uma experiência na formação inicial de professores. Química Nova, São Paulo: SBQ, 36(7), 1066-1072.

Brasil. Ministério Da Educação/Inep. (2004). Qualidade da Educação: uma nova leitura do desempenho dos estudantes da $3^{\underline{a}}$ série do Ensino Médio. Brasília: MEC/INEP. Disponível em: $<$ http://download.inep.gov.br/download/saeb /2004/qualidade_educacao.pdf> Acesso em: 24 nov. 2013.

Brasil. Ministério Do Meio Ambiente. Compostagem. Disponível em: $<$ http://www.mma.gov.br/component/k2/item /7594-compostagem> Acesso em: 11 nov. de 2013.

Moura, D. G. (2010). Feira De Ciências: Necessidades de Novas Diretrizes. Disponível em:

$<$ http://www.tecnologiadeprojetos.com.br>. Acesso em: 02 dez. 2013.

Monteiro, N. J., Simões, V. H. F., Ramires, V. R. M. (2013). Utilização da etapa de planejamento do ciclo PDCA para análise e proposição de solução de um problema de um centro técnico automotivo de Belém do Pará. In: Encontro Nacional de Engenharia de Produção. Salvador. Anais... Rio de Janeiro: ABEPRO, 08-11, out. 2013. Disponível em: $<$ http://www.abepro.org.br/biblioteca/enegep 2013_TN_STO_178_019_22012.pdf> Acesso em: 07 dez. 2013.

Morrison, R. T., Boyd, R. N. (1996). Química Orgânica, 13. ed. Lisboa: Fundação Calouste Gulbenkian.

Saint-Georges, P. (1997). Pesquisa E Crítica Das Fontes De Documentação nos domínios econômicos, social e político. In: ALBARELLO, Luc; DIGNEFFE, Françoise; HIERNAUX, Jean-Pierre Práticas e métodos de investigação em ciências sociais. Lisboa: Gradiva Publicações Ltda, 1997.

Sanson, A. L., Baeta, B. E. L., Rodrigues, K. L. T., Afonso, R. J. C. F. (2013). Equipamento de baixo custo para extração em fase sólida em amostras aquosas de grande volume utilizando pressão positiva de N2. Química Nova, São Paulo: SBQ, 09(36), 214-217.

Silva, P. B., Bezerra, V. S., Grego, A., Souza, L. H. A. (2008). A Pedagogia de Projetos no Ensino de Química - O Caminho das Águas na Região Metropolitana do Recife: dos Mananciais ao Reaproveitamento dos Esgotos. Química Nova, São Paulo: SBQ, 36(29) 14-19.

Bregunce, D., Brito, A. S., Bregunce, D. T., Moraes, F. M., Cubas, S. A., Maranho, L. T. (2007). Avaliação do sistema wetland construído para tratamentos de águas urbanas altamente poluídas com esgoto sanitário. In: Congresso Brasileiro de Engenharia Sanitária e Ambiental, 24., 2007, Belo Horizonte, SBEA, 24-27.

Werkema, C. (1995). Ferramentas estatísticas básicas para o gerenciamento de processos. Volume 2. Belo Horizonte: UFMG. 